\title{
In vitro enzyme inhibitory and cytotoxic studies with Evolvulus alsinoides (Linn.) Linn. Leaf extract: a plant from Ayurveda recognized as Dasapushpam for the management of Alzheimer's disease and diabetes mellitus
}

Pavithra Mettupalayam Kaliyannan Sundaramoorthy ${ }^{*}$ and Kannan Kilavan Packiam

\begin{abstract}
Background: Evolvulus alsinoides (Linn.) Linn. (Convolvulaceae) is a therapeutic herb alleviating brain patterns associated with three categories of regulatory principles of the body, mind, and behaviour. In the current research, enzyme inhibition and cytotoxic potentials of E. alsinoides (L.) L. leaf extract has been studied validating its potential application.

Methods: The plant phenolics in the leaf extracts obtained via cold-maceration with solvents viz: n-hexane, chloroform, ethyl acetate, methanol, and water were quantitatively analyzed. The antioxidant potency was evaluated using 2,2-diphenyl-1-picrylhydrazyl (DPPH) and Ferric Reducing Ability of Plasma (FRAP) assays at five concentrations $(100-500 \mu \mathrm{g})$. The enzyme inhibition potential was performed with a-amylase, a-glucosidase, and acetylcholinesterase at seven concentrations $(25-500 \mu \mathrm{g})$. The experiments were done in triplicates and statistically validated using Minitab-17 and SPSS 22.

Results: Water extract contain $45.08 \pm 0.02 \mathrm{mg} \mathrm{GAE} / \mathrm{g}, 49.30 \pm 0.07 \mathrm{mg} \mathrm{GAE} / \mathrm{g}, 211.21 \pm 0.02 \mathrm{mg}$ QE/g tannins, phenolics, flavonoids respectively. Its antioxidant activity was supported by $I_{50} 52.43 \pm 0.2 \mu \mathrm{g} / \mathrm{mL}$ (DPPH assay) and $41.58 \pm 0.03$ (FRAP assay). Methanolic extract inhibits a-amylase with $I C_{50} 1.33 \pm 0.05 \mu \mathrm{g} / \mathrm{mL}$. Water extract inhibits a-glucosidase and acetylcholinesterase with $I_{50} 3.58 \pm 0.02 \mu \mathrm{g} / \mathrm{mL}$ and $4.46 \pm 0.03 \mu \mathrm{g} / \mathrm{mL}$. Cytotoxicity studies with SH-SY5Y cell-line substantiate the inhibition potential of water extract with $\mathrm{IC}_{50} 103.0035 \mu \mathrm{g} / \mathrm{mL}$.
\end{abstract}

Discussion and conclusions: The extracts with potent antioxidant and enzyme-inhibiting activity were determined. The findings of the research are the first report about the inhibition effects of Evolvulus alsinoides (Linn.) Linn extracts against a-amylase, a-glucosidase and acetylcholinesterase. The extracts shall be examined in future studies to evaluate its pharmaceutical potential.

Keywords: Evolvulus alsinoides (Linn.) Linn., Enzyme inhibition, Alzheimer's disease, Hyperglycemia, Neuronal disorder, Pearson correlation, Neuroblastoma cell lines, Bioactivity

\footnotetext{
* Correspondence: pavithramks@bitsathy.ac.in

Department of Biotechnology, Bannari Amman Institute of Technology,

Sathyamangalam, Tamilnadu, India
} 


\section{Background}

Evolvulus alsinoides (Linn.) Linn. (Convolvulaceae) commonly called as Vishnukranti, is a prostrate perennial herb native of Indian origin from tropical and subtropical swampy regions. The plant extracts rejuvenate nervous system, increases sexual power, discharge phlegm and humour from the body, promoting sleep. In Ayurvedic medicine, the whole plant was used as brain tonic and as hepatoprotective [1], amnesia and asthma [2]. Chief phytochemicals in the plant extract are $\beta$ sitosterol, scopolin, scopoletin, umbelliferon, triacontane, shankpushpine and betaine. Traditionally local practitioners use this plant extract in the treatment of various neurodegenerative diseases. The earlier reports on therapeutical aspects of the plant encouraged us to carry out the pharmacological activity in this current research. Extraction and phytochemical analysis form the fundamental principle in the isolation of therapeutically active molecules from plant tissues to explore its bioactive potential [3].

Herbal medicines are utilized as traditional and alternative therapy to precisely restore declining cognitive functions. The secondary metabolites present in the medicinal plants possess a wide range of therapeutical properties [4]. The medicinal plant's aid in retarding the vital metabolic pathways or inhibiting the enzymes is responsible for the biochemical reactions. Moreover, herbal bioactive claims its rewards for their effectiveness, safety and acceptability [5]. Medicinal plants have been regarded as a promising source of lead molecules for new drug development [6].

A neurodegenerative disease that demolishes brain cells leading to distress in thinking, memory, and behaviour is Alzheimer's Disease (AD) [7]. There is seldom appropriate medication that could restore the normal functions of the brain [8]. To date, no specific treatment for the management of $\mathrm{AD}$ has recognized [9]. Acetylcholine Esterase (AChE) are serine hydrolases present in various tissues of the body. AChE terminates signal transmission at cholinergic synapses by hydrolysis of acetylcholine into choline and acetate [3]. AChE possesses a complex molecular polymorphism of quaternary structure in the tissues. The various forms are similar in catalytic activity but differ in hydrophobic interactions and ionic or hydrodynamic parameters [10]. In vitro studies have reported that Acetylcholinesterase (AChE) persuades formation of amyloid fibrils resulting in acetylcholinesterase- beta-amyloid peptide (A $\beta$ ) complex that is highly toxic to the brain cells [9]. These complexes get deposited in the brain as amyloid plaques resulting in Alzheimer's Disease [11]. Amyloid plaques are suitable targets in Alzheimer's treatment. Acetylcholinesterase (AChE) prevails to be an appropriate target for systematic progress in Alzheimer's treatment.
Treatments with AChE Inhibitors are beneficial in enhancing cognitive malfunction and are most effective in mending perceptive responses [12].

The preliminary studies and epidemiological data proposed that Alzheimer's Disease as “Type 3 Diabetes". Earlier studies had reported that correlation between insulin resistance and phosphorylation of tau proteins, heading to the inception and progression of neurodegeneration [13]. Previous studies reported the defects with insulin production and its consequences affecting the central nervous system modulating cognitive function. Reduced insulin signalling and insulin resistance in the brain compete for a substantial role in the pathogenesis of AD. Clinical trials with Humans have proven the efficacy of some oral antidiabetic medications in the improvement of cognition [14].

Diabetes mellitus is a lingering ailment occurred owing to futile utilization of insulin in the body. This condition, called hyperglycemia is a usual risk linked with an increase in the production of free radicals causing tissue injury leading to diabetes. Treatment for diabetes includes control of postprandial hyperglycemia [15]. $\alpha$ Amylase acts on 1,4-glycosidic linkages in the polysaccharides and converting into disaccharides. $\alpha$ Glucosidase are enzymes that act upon the disaccharides producing monosaccharides increasing glucose levels in blood [16]. Inhibition of the two enzymes, $\alpha$-Amylase and $\alpha$-Glucosidase, becomes a promising approach for diabetes treatment. The inhibition of these enzymes regulates delayed carbohydrate metabolism, decreased glucose retention rate with diminished postprandial plasma glucose level [17]. A wide range of natural and synthetic pharmaceuticals are used to inhibit $\alpha$-glucosidase and $\alpha$ amylase [18], thereby reducing blood glucose level aiding in ruling out type 2 diabetes [19]. However, synthetic inhibitors produce adverse effects such as abdominal pain, diabetic ketoacidosis, colonic ulcerations. Hence, nutraceuticals from plants of therapeutic importance are efficient enzyme inhibitors for the management or treatment of metabolic disorders [20].

In the present investigation, neuroprotective and antidiabetic potential of $E$. alsinoides leaf extract was examined. The enzyme inhibition potential of the plant extracts for $\alpha$-amylase, $\alpha$-glucosidase and acetylcholinesterase were determined. The current research is the first-time report on the effect of $E$. alsinoides plant extract in inhibiting the viability of neuroblastoma cell lines.

\section{Methods}

Plant material

E. alsinoides (L.) L was collected in a closed paper bag during the flowering season in 2016 from the Western Ghats of Sathyamangalam, Tamilnadu, India and 
processed in the laboratory. The plant was authenticated at Botanical Survey of India, Coimbatore, Tamil Nadu India [Ref no.: BSI/SRC/5/23/2016/Tech/1711 Dated 27.10.2016]. After authentication, the leaves were removed, washed thoroughly in distilled water, to remove the debris thnen shade dried, powdered and stored in amber bottles [21].

\section{Preparation of plant extracts}

The powdered raw material $(20 \mathrm{~g})$ was defatted using pet ether. The defatted sample was successively extracted with $250 \mathrm{~mL}$ n-hexane, chloroform, ethyl acetate, methanol, and water by cold maceration method. The extracts were labelled as $\mathrm{H}, \mathrm{CH}, \mathrm{EA}, \mathrm{M}, \mathrm{W}$ respectively and used alike in all the assays and results. The fat-rich pet ether fraction labelled as $\mathrm{P}$ in all subsequent experiments. The solvent-soluble constituents were extracted using the cold maceration method at room temperature with continuous shaking by periodic replacement of fresh solvent every $24 \mathrm{~h}$ [22]. The process was repeated thrice with new solvent. Subsequently, extracts were filtered through double-layered cheesecloth under vacuum and concentrated at reduced pressure at $40^{\circ} \mathrm{C}$ using a rotary evaporator (Make: Cyberlab, USA \& Model: CR2000) and freeze-dried using Freeze Dryer (Make: Martin Christ - Germany, Model: Alpha 1-2 LD Plus) and stored in an airtight container at $4{ }^{\circ} \mathrm{C}$ [23].

\section{Gas chromatography and mass spectroscopy (GCMS) analysis}

The plant extracts $(1 \mathrm{mg} / \mathrm{ml})$ were dissolved in the appropriate solvent and subjected to GCMS analysis using GC system (Agilent Technologies $6890 \mathrm{~N}$ ) coupled with Mass spectroscopy (JEOL). Capillary column fused with silica elutes the biomolecules. The system parameters were injection temperature $-220^{\circ} \mathrm{C}$, initial oven temperature $-50^{\circ} \mathrm{C}$ increasing up to $250^{\circ} \mathrm{C}$ at a rate of $10^{\circ} \mathrm{C}$ per min, carrier gas system - Helium (flow rate: 1 $\mathrm{mL} / \mathrm{min}$ ) and interface temperature $-250{ }^{\circ} \mathrm{C}$. The volatiles was identified by comparing the spectrum with National Institute of Standards and Technology (NIST) Chemical Web book database [12]. Pubchem database (https://pubchem.ncbi.nlm.nih.gov/) was used to determine the name, molecular weight and structure of the phytochemicals in the extract.

\section{Determination of plant Phenolics}

The concentration of Tannins and Total Phenolic Compounds $[\mathrm{TPC}]$ in the extracts was determined using the Folin-Ciocalteu method. The concentration of Total Flavonoid Compounds [TFC] was determined through aluminium chloride spectrophotometric methods. Tannic acid was used as a standard for estimating total tannins $\left(Y=3.814 x+0.019, R^{2}=0.995\right)$ and were expressed as Tannic Acid Equivalents (TAE). Gallic acid was used for constructing the standard curve $(\mathrm{Y}=6.720 \mathrm{x}+0.036$, $\left.\mathrm{R}^{2}=0.994\right)$ and the results were expressed as $\mathrm{mg}$ of gallic acid equivalents/g of extract (GAEs) for the total phenolic compounds. Total Flavonoid Content in the extract were expressed as milligrams quercetin equivalents per gram dry extract $(\mathrm{mg} \mathrm{QE} / \mathrm{g})$ with the calibration curve, $\mathrm{Y}=0.012 \mathrm{x}-0.104, \mathrm{R}^{2}=0.995$ with standard quercetin [24].

\section{Antioxidant activities}

The functional groups possessed by the plant material determine its antioxidant potential. Usage of a single method to evaluate and correlate the antioxidant activity of the compounds is unreceptive. Two significant radical scavenging assays were performed such as 2,2-diphenyl1-picrylhydrazyl assay (DPPH) and Ferric Reducing of Antioxidant Power Assay (FRAP). Soluble fractions were prepared in the concentration of $0.025-0.5 \mathrm{mg} / \mathrm{mL}$ for the tests. The $\mathrm{IC}_{50}$ values for each extract were determined by plotting inhibition percentage and sample concentration.

\section{DPPH Radical Screening Activity}

Standard methods with certain modifications were used for determining free radical scavenging ability of the extracts. Alcoholic DPPH solution was prepared by dissolving DPPH $(2.4 \mathrm{mg})$ in absolute methanol $(100 \mathrm{~mL})$. Test sample $5 \mu \mathrm{L}$ was added to $3995 \mu \mathrm{L}$ methanolic $\mathrm{DPPH}$ and vortexed vigorously. The reaction mixture was kept at room temperature for $30 \mathrm{~min}$ in complete darkness. The absorbance was read at $515 \mathrm{~nm}$ using a spectrophotometer with butylated hydroxytoluene (BHT) as a positive control [25]. The capability of the plant extracts to scavenge the DPPH radical was calculated, and $\mathrm{IC}_{50}$ values were determined for each extract.

\section{Total antioxidant activity (FRAP assay)}

The antioxidant competence of the extracts was evaluated using 2,4,6-tripyridyl-S-triazine (TPTZ) in $\mathrm{FeCl}_{3} \cdot 6 \mathrm{H}_{2} \mathrm{O}$ solution. Reduction of colourless $\mathrm{Fe}^{3+} \mathrm{TPTZ}$ complex to blue-coloured $\mathrm{Fe}^{2+}$-tripyridyltriazine at low $\mathrm{pH}$ by the presence of electron-donating antioxidants was determined. This reaction was measured by computing the absorbance at $593 \mathrm{~nm}$. The constituents of Ferric Reducing Antioxidant Power (FRAP) reagent are $300 \mathrm{mM}$ acetate buffer, $10 \mathrm{~mL}$ TPTZ in $40 \mathrm{mM} \mathrm{HCl}$ and $20 \mathrm{mM} \mathrm{FeCl} 3 \cdot 6 \mathrm{H}_{2} \mathrm{O}$ in the ratio of $10: 1: 1$ at $37^{\circ} \mathrm{C}$. For each reaction, Diluted plant sample $(5 \mu \mathrm{L})$ of was added to $3995 \mu \mathrm{L}$ fresh FRAP reagent and mixed using a vortex mixer and incubated for $30 \mathrm{~min}$ at $37^{\circ} \mathrm{C}$. The absorbance was read at $593 \mathrm{~nm}$ with ascorbic acid as standard [26]. The reducing potential of the extracts was measured, and $\mathrm{IC}_{50}$ value was determined for each extract. 


\section{Acetylcholinesterase inhibition assay}

The Acetylcholinesterase inhibitory capacity of each extract was determined using the Ellman method with necessary modification [27]. Briefly, for each assay, $50 \mu \mathrm{L}$ of $3 \mathrm{mM} \mathrm{5,5}$ 'dithiobis nitro benzoic acid, $50 \mu \mathrm{L}$ AChE $(0.5 \mathrm{mg} / \mathrm{mL}$ ) enzyme from Electrophorus electricus (Type $\mathrm{V}-\mathrm{S}$, lyophilized powder, $\geq 1000 \mathrm{units} / \mathrm{mg}$ protein in Tris- $\mathrm{HCl}$ buffer $(\mathrm{pH}=8.0)), 35 \mu \mathrm{L}$ Tris $\mathrm{HCL}(50 \mathrm{mM}$, $\mathrm{pH} 8.0)$ and plant extracts $(25-500 \mu \mathrm{g})$ was mixed and incubated at $37^{\circ} \mathrm{C}$ for $10 \mathrm{~min}$ in a micro-titre plate. Addition of $25 \mu \mathrm{L}$ acetylthiocholineiodide $(15 \mathrm{mM})$ initiates the reaction. The blank solution contains all the reagents except the enzyme. The absorbance was recorded at $412 \mathrm{~nm}$ after $10 \mathrm{~min}$ incubation at $37^{\circ} \mathrm{C} . \mathrm{IC}_{50}(\mu \mathrm{g} / \mathrm{mL})$ of the extracts that inhibit the enzyme activity was determined.

\section{a-Amylase inhibition assay}

Caraway-Somogyi method [28] with necessary adjustments was adopted to perform the $\alpha$-Amylase inhibitory activity of the plant extract. Each extract at different concentration $(25-500 \mu \mathrm{g})$ was added to $50 \mu \mathrm{L} \alpha-$ amylase $(1 \mathrm{mg} / \mathrm{mL})$ in phosphate buffer $(\mathrm{pH}=6.9)$ in 96 well microtiter plate and incubated at $37^{\circ} \mathrm{C}$ for $10 \mathrm{~min}$. Addition of starch solution $(50 \mu \mathrm{L}, 0.05 \%)$ initiates the reaction. After $10 \mathrm{~min}$ of incubation at $37^{\circ} \mathrm{C}$, slower addition of $1 \mathrm{M} \mathrm{HCl}(25 \mu \mathrm{L})$ stops the reaction. One hundred microliter Iodine solution was added to the reaction mix. Correspondingly, the control contains all reaction components except the enzyme. The absorbance of the sample was determined at $630 \mathrm{~nm}\left(\mathrm{iMark}^{\mathrm{Tm}}\right.$ Microplate Reader - catalogue \#: 168-1130). The percentage of inhibition for each extract at its varying concentration and $\mathrm{IC}_{50}(\mu \mathrm{g} / \mathrm{mL})$ were calculated.

\section{a-Glucosidase inhibition assay}

The inhibitory potency of the extract towards $\alpha$ glucosidase was determined using maltose as the substrate in a micro-titer plate. Both $\alpha$-glucosidase and maltose were dissolved in $10 \mathrm{mM}$ phosphate buffer $(\mathrm{pH}$ 6.86). Forty microliter extract at the varying concentration $(25-500 \mu \mathrm{g})$ was prepared using $10 \mathrm{mM}$ phosphate buffer and was mixed with $40 \mu \mathrm{L} \alpha$-glucosidase $(0.3 \mathrm{U} /$ $\mathrm{mL}$ ). After incubation for $5 \mathrm{~min}$ at $37^{\circ} \mathrm{C}, 20 \mu \mathrm{L}$ maltose $(2 \mathrm{mM})$ was added to start the reaction. The reaction mixture was incubated at $37{ }^{\circ} \mathrm{C}$ for $15 \mathrm{~min}$ and stopped by adding $50 \mu \mathrm{L}$ methanol. The absorbance of the sample and blank was read at $695 \mathrm{~nm}$. The $\alpha$-glucosidase inhibitory activity was expressed as $\mathrm{IC}_{50}(\mu \mathrm{g} / \mathrm{mL})[29]$.

\section{Cytotoxicity studies using SH-SY5Y cell line by MTT assay}

The human neuroblastoma cell line, SH-SY5Y is known as a relevant cellular model for biochemical investigations on Alzheimer's disease (AD). SH-SY5Y cells are also known as neurosteroid-producing cells which express the chief steroidogenic enzymes [30]. The cell count of SH-SY5Y, neuroblastoma cell line was adjusted to $1.0 \times 10^{5}$ cells $/ \mathrm{mL}$ using DMEM medium containing $10 \%$ FBS. To each well of a 96 well flat bottom microtitre plate, $100 \mu \mathrm{L}$ of diluted cell suspension $(70-80 \%$ confluence) was added. After $24 \mathrm{~h}$, at a sufficient population, the cells were centrifuged, and the pellets were suspended at four concentrations viz. 31.25, 62.5, 125, $250 \mu \mathrm{g} / \mathrm{mL}$. Then, the plates were incubated for $48 \mathrm{~h}$ at $37^{\circ} \mathrm{C}$ in a $5 \% \mathrm{CO}_{2}$ atmosphere for microscopic examination, and the observations were recorded every $24 \mathrm{~h}$. After $48 \mathrm{~h}, 20 \mu \mathrm{l}$ of MTT $(2 \mathrm{mg} / \mathrm{mL})$ was added to MEM-PR (MEM without phenol red) and shaken gently. The plates were further incubated for $2 \mathrm{~h}$ at $37^{\circ} \mathrm{C}$ in $5 \%$ $\mathrm{CO}_{2}$ atmosphere. DMSO $(100 \mu \mathrm{l})$ was added slowly to the plates and gently shaken to solubilize the formed formazan. Absorbance was read at $540 \mathrm{~nm}$ using the microplate reader. Per cent cell viability and concentration of extract required to inhibit cell growth by $50 \%$ were obtained from dose-response curve [31].

\section{Statistical analysis}

All the assays were carried out in triplicates, and the results expressed as mean \pm standard error mean (SEM). The statistical analysis was performed with one-way ANOVA using Minitab-17 Statistical Software Package. Linear regression analysis was carried out to determine $\mathrm{IC}_{50}$ values. Bivariate correlation analysis was done using IBM SPSS Statistics 22.0. Pearson's correlation coefficient was determined and found to be significant.

\section{Results}

GCMS analyses

A total of 97 different compounds were identified in the five crude extracts. The biomolecules conferred by the plant extracts were identified with the help of spectrum deposited at the NIST library and were summarized in Table 1.

The most prevailing compounds present in the plant extracts were 2-(2-ethylhexoxycarbonyl) benzoic acid, (2E)-6-methoxy-2-[(4-methoxyphenyl)methylidene]-3,4dihydronaphthalen-1-one, 8,8-Dimethyl-3,3a,4,5,6,7,8,8boctahydro-2H-indeno [1,2-b]furan-2-one,3-[2-(1-methylimidazol-2-yl)sulfanylacetyl]chromen-2-one, Phenol,2,6bis (1,1-dimethylethyl)-4-[(4-hydroxy-3,5-dimethylphenyl)methyl], [4-(7-acetyloxy-5-methoxy-4-oxochromen2-yl)phenyl] acetate, 4(3H)-Quinazolinone and 3-(4hydroxyphenyl)-2-(2-phenylethenyl).

\section{Estimation of plant Phenolics}

The Total Phenolic Content (TPC) of all extracts was determined in terms of $\mathrm{mg}$ of Gallic Acid equivalents per g extract (mg GAE/g), and the results were displayed 
Table 1 Results of GCMS Analysis of E.alsinoides (L.) L. leaf extracts

\begin{tabular}{|c|c|c|c|c|c|c|c|}
\hline S.No & Solvent & RT & Compound & CAS Registry & $\begin{array}{l}\text { Molecular } \\
\text { Weight } \\
\mathrm{g} / \mathrm{mol}\end{array}$ & $\begin{array}{l}\text { Molecular } \\
\text { formula }\end{array}$ & Activities Reported \\
\hline 1. & Hexane & 20.22 & Tridecanoic acid, methyl ester & $1731-88-0$ & 228.376 & $\mathrm{C}_{14} \mathrm{H}_{28} \mathrm{O}_{2}$ & Antibacterial and Antifungal \\
\hline 2. & & 21.8 & Phytol & $150-86-7$ & 296.539 & $\mathrm{C}_{20} \mathrm{H}_{40} \mathrm{O}$ & $\begin{array}{l}\text { Antinociceptive and } \\
\text { Antioxidant Activities }\end{array}$ \\
\hline 3. & & 26.32 & 2-(2-ethylhexoxycarbonyl) benzoic acid & $4376-20-9$ & 278.348 & $\mathrm{C}_{16} \mathrm{H}_{22} \mathrm{O}_{4}$ & Anti-depressant \\
\hline 4. & & 14.62 & 2,4-Di-tert-butylphenol & $96-76-4$ & 206.323 & $\mathrm{C}_{14} \mathrm{H}_{22} \mathrm{O}$ & Anti-fungal \\
\hline 5. & & 21.47 & 13-Hexyloxacyclotridec-10-en-2-one & $127,062-51-5$ & 280.445 & $\mathrm{C}_{18} \mathrm{H}_{32} \mathrm{O}_{2}$ & Antitumor activity \\
\hline 6. & & 23.73 & $\begin{array}{l}\text { (2E)-6-methoxy-2-[(4-methoxyphenyl) } \\
\text { methylidene]-3,4-dihydronaphthalen-1-one }\end{array}$ & $87,384-01-8$ & 294.344 & $\mathrm{C}_{19} \mathrm{H}_{18} \mathrm{O}_{3}$ & No activity reported \\
\hline 7. & Ethylacetate & 14.17 & Gamma-Terpineol & $586-81-2$ & $\mathrm{C}_{10} \mathrm{H}_{18} \mathrm{O}$ & 154.253 & Aroma \\
\hline 8. & & 15.28 & methyl (2Z,6E)-3,7-dimethyldeca-2,6-dienoate & $55,283-14-2$ & $\mathrm{C}_{13} \mathrm{H}_{22} \mathrm{O}_{2}$ & 210.317 & No activity reported \\
\hline 9. & & 17.2 & methyl tridecanoate & $1731-88-0$ & $\mathrm{C}_{14} \mathrm{H}_{28} \mathrm{O}_{2}$ & 228.376 & Anticancer \\
\hline 10. & & 18.85 & methyl (13E,16E)-octadeca-13,16-dienoate & $56,846-99-2$ & $\mathrm{C}_{19} \mathrm{H}_{34} \mathrm{O}_{2}$ & 294.479 & No activity reported \\
\hline 11. & & 19.77 & 2-[(9Z,12Z)-octadeca-9,12-dienoxy]ethanol & $17,367-08-7$ & $\mathrm{C}_{20} \mathrm{H}_{38} \mathrm{O}_{2}$ & 310.522 & No activity reported \\
\hline 12. & & 20.92 & $\begin{array}{l}\text { 5,7-dihydroxy-2-(4-methoxyphenyl)chromen-4- } \\
\text { one (Acacetin) }\end{array}$ & $480-44-4$ & $\mathrm{C}_{16} \mathrm{H}_{12} \mathrm{O}_{5}$ & 284.267 & Inhibits neuronal cell death \\
\hline 13. & & 22.27 & $\begin{array}{l}\text { 3-[2-(1-methylimidazol-2- } \\
\text { yl)sulfanylacetyl]chromen-2-one }\end{array}$ & - & $\mathrm{C}_{15} \mathrm{H}_{12} \mathrm{~N}_{2} \mathrm{O}_{3} \mathrm{~S}$ & 300.332 & No activity reported \\
\hline 14. & Chloroform & 12.93 & 1-methyl-2-prop-2-enylsulfanylbenzene & $24,309-31-7$ & 164.266 & $\mathrm{C}_{10} \mathrm{H}_{12} \mathrm{~S}$ & $\begin{array}{l}\text { Used in olefin } \\
\text { polymerization }\end{array}$ \\
\hline 15. & & 15.53 & Quinoline, 5-nitro, 1 - oxide & $7613-19-6$ & 190.158 & $\mathrm{C}_{9} \mathrm{H}_{6} \mathrm{~N}_{2} \mathrm{O}_{3}$ & Anti-inflammatory \\
\hline 16. & & 16.15 & $\begin{array}{l}\text { 8,8-Dimethyl-3,3a,4,5,6,7,8,8b-octahydro- } 2 \mathrm{H} \text { - } \\
\text { indeno[1,2-b]furan-2-one }\end{array}$ & - & 206.281 & $\mathrm{C}_{13} \mathrm{H}_{18} \mathrm{O}_{2}$ & No activity reported \\
\hline 17. & & 17.45 & Cetylic acid & $57-10-3$ & 256.43 & $\mathrm{C}_{16} \mathrm{H}_{32} \mathrm{O}_{2}$ & Biosynthesis of lung lecithin \\
\hline 18. & & 18.45 & 16-Octadecenoic acid, methyl ester & $56,554-49-5$ & 296.495 & $\mathrm{C}_{19} \mathrm{H}_{36} \mathrm{O}_{2}$ & No activity reported \\
\hline 19. & & 21.08 & $\begin{array}{l}\mathrm{N} \text {-[4-(4,4-Diethyl-1,4-dihydro-2H-benzo(d) [1, 32] } \\
\text { oxazin-2-yl)-phenyl]-acetamide }\end{array}$ & $\begin{array}{l}626,409 \\
\text { (Pubchem) }\end{array}$ & 324.424 & $\mathrm{C}_{20} \mathrm{H}_{24} \mathrm{~N}_{2} \mathrm{O}_{2}$ & No activity reported \\
\hline 20. & & 24.25 & $\begin{array}{l}\text { Quinazolin-4(3H)-one, 3-(3-methoxyphenyl)-2-(2- } \\
\text { phenylethenyl)- }\end{array}$ & $112,750-80-8$ & 354.4 & $\mathrm{C}_{22} \mathrm{H}_{16} \mathrm{~N}_{2} \mathrm{O}_{2}$ & No activity reported \\
\hline 21. & & 25.38 & $\begin{array}{l}\text { Benzoic acid, 2,4-dimethoxy-6-methyl-, (8,8- } \\
\text { dimethoxy-2-octyl) ester }\end{array}$ & $312,305-56$ & 368.5 & $\mathrm{C}_{20} \mathrm{H}_{32} \mathrm{O}_{6}$ & No activity reported \\
\hline 22. & & 26.33 & $2,3,16,17$-Octadecanetetraone tetraoxime & $34,959-24$ & 370.486 & $\mathrm{C}_{18} \mathrm{H}_{34} \mathrm{~N}_{4} \mathrm{O}_{4}$ & No activity reported \\
\hline 23. & & 22.47 & Tricosan-2-ol & - & 340.636 & $\mathrm{C}_{23} \mathrm{H}_{48} \mathrm{O}$ & No activity reported \\
\hline 24. & Ethanol & 18.33 & Octadecanoic acid & $57-11-4$ & $\mathrm{C}_{18} \mathrm{H}_{36} \mathrm{O}_{2}$ & 284.484 & $\begin{array}{l}\text { Anti-viral and anti- } \\
\text { inflammatory activities }\end{array}$ \\
\hline 25. & & 21.57 & octadecyl 2-methoxyacetate & - & $\mathrm{C}_{21} \mathrm{H}_{42} \mathrm{O}_{3}$ & 342.564 & No activity reported \\
\hline 26. & & 17.55 & [2-(4-Ethyl-phenyl)-4-methyl-2H-phthalazin-1-one] & - & - & - & No activity reported \\
\hline 27. & & 20.18 & Nonadecane-2,4-dione & $16,577-69-8$ & $\mathrm{C}_{19} \mathrm{H}_{36} \mathrm{O}_{2}$ & 296.495 & Antihistamine activity \\
\hline 28. & Methanol & 13.43 & Phenol,2-propyl- & $644-35-9$ & $\mathrm{C}_{9} \mathrm{H}_{12} \mathrm{O}$ & 136.194 & Flavouring agent \\
\hline 29. & & 14.12 & Flavone & $525-82-6$ & 222.243 & $\mathrm{C}_{15} \mathrm{H}_{10} \mathrm{O}_{2}$ & Anti-inflammatory \\
\hline 30. & & 14.17 & 7-methoxy-2-oxochromene-3-carboxylic acid & $20,300-59-8$ & $\mathrm{C}_{11} \mathrm{H}_{8} \mathrm{O}_{5}$ & 220.18 & Antitumor \\
\hline 31. & & 16.15 & cyclohexadec-5-en-1-one & $37,609-25-9$ & $\mathrm{C}_{16} \mathrm{H}_{28} \mathrm{O}$ & 236.399 & Fragrance \\
\hline 32. & & 17.12 & methyl hexadecanoate & $112-39-0$ & $\mathrm{C}_{17} \mathrm{H}_{34} \mathrm{O}_{2}$ & 270.457 & $\begin{array}{l}\text { Laundry and Dishwashing } \\
\text { Products }\end{array}$ \\
\hline 33. & & 18.85 & Methyl oleate & $112-62-9$ & $\mathrm{C}_{19} \mathrm{H}_{36} \mathrm{O}_{2}$ & 296.495 & Emulsifiers \\
\hline 34. & & 20.98 & Isopropyl stearate & $112-10-7$ & $\mathrm{C}_{21} \mathrm{H}_{42} \mathrm{O}_{2}$ & 326.565 & $\begin{array}{l}\text { Lubricant and solvent in } \\
\text { pharmaceutical formulations }\end{array}$ \\
\hline 35. & & 22.82 & Phenol, 2,6-bis(1,1-dimethylethyl)-4-[(4-hydroxy- & $20,690-84-0$ & $\mathrm{C}_{23} \mathrm{H}_{32} \mathrm{O}_{2}$ & 340.507 & No activity reported \\
\hline
\end{tabular}


Table 1 Results of GCMS Analysis of E.alsinoides (L.) L. leaf extracts (Continued)

\begin{tabular}{|c|c|c|c|c|c|c|c|}
\hline S.No & Solvent & RT & Compound & CAS Registry & $\begin{array}{l}\text { Molecular } \\
\text { Weight } \\
\mathrm{g} / \mathrm{mol}\end{array}$ & $\begin{array}{l}\text { Molecular } \\
\text { formula }\end{array}$ & Activities Reported \\
\hline & & & 3,5-dimethylphenyl)methyl]- & & & & \\
\hline 36. & & 24.3 & $\begin{array}{l}\text { (1Z,5Z)-1,6-dihydroxy-1,6-bis(3- } \\
\text { methoxyphenyl)hexa-1,5-diene-3,4-dione }\end{array}$ & - & $\mathrm{C}_{20} \mathrm{H}_{18} \mathrm{O}_{6}$ & 354.358 & No activity reported \\
\hline 37. & Water & 9.23 & Phenol - 2 - propyl & 644-35-9 & $\mathrm{C}_{9} \mathrm{H}_{12} \mathrm{O}$ & 136.19 & Food additive \\
\hline 38. & & 10 & 2-methyl-5-phenyl-1H-pyrazol-3-one & $34,347-81-4$ & $\mathrm{C}_{10} \mathrm{H}_{10} \mathrm{~N}_{2} \mathrm{O}$ & 174.2 & Antiviral and Anticancer \\
\hline 39. & & 14.12 & 1-naphthalen-1-ylbut-3-en-1-ol & - & $\mathrm{C}_{14} \mathrm{H}_{14} \mathrm{O}$ & 198.26 & $\begin{array}{l}\text { Drugs for disorders of the } \\
\text { nervous system }\end{array}$ \\
\hline 40. & & 14.87 & 1-methoxy-4-[(4-methoxyphenyl)methyl] benzene & $726-18-1$ & $\mathrm{C}_{15} \mathrm{H}_{16} \mathrm{O}_{2}$ & 228.29 & Anticancer \\
\hline 41. & & 16.02 & methyl 13-methylpentadecanoate & $5487-50-3$ & $\mathrm{C}_{17} \mathrm{H}_{34} \mathrm{O}_{2}$ & 270.5 & Antimicrobial \\
\hline 42. & & 16.6 & hexadecanoic acid & $57-10-3$ & $\mathrm{C}_{16} \mathrm{H}_{32} \mathrm{O}_{2}$ & 256.42 & Flavouring Agent \\
\hline 43. & & 17.6 & methyl (E)-octadec-10-enoate & $13,481-95-3$ & $\mathrm{C}_{19} \mathrm{H}_{36} \mathrm{O}_{2}$ & 296.5 & Anticancer \\
\hline 44. & & 18.25 & $\begin{array}{l}\text { 3-[2-(1-methylimidazol-2-yl)sulfanylacetyl] } \\
\text { chromen-2-one }\end{array}$ & $383,152-05-4$ & $\mathrm{C}_{15} \mathrm{H}_{12} \mathrm{~N}_{2} \mathrm{O}_{3} \mathrm{~S}$ & 300.3 & Anticancer \\
\hline 45. & & 19.05 & 1-Ethyl-4-[(4-hexylphenyl)ethynyl]benzene & $117,923-34-9$ & $\mathrm{C}_{22} \mathrm{H}_{26}$ & 290.4 & - \\
\hline 46. & & 20.28 & 11-methylidenetricosane & $51,732-26-4$ & $\mathrm{C}_{24} \mathrm{H}_{48}$ & 336.6 & Cosmetic Preparation \\
\hline 47. & & 21.7 & (E)-octadec-9-enoic acid & $112-79-8$ & $\mathrm{C}_{18} \mathrm{H}_{34} \mathrm{O}_{2}$ & 282.5 & Food Additive \\
\hline 48. & & 23.59 & $\begin{array}{l}\text { 4-[(3,5-ditert-butyl-4-hydroxyphenyl)methyl]- } \\
\text { 2,6-dimethylphenol }\end{array}$ & $20,690-84-0$ & $\mathrm{C}_{23} \mathrm{H}_{32} \mathrm{O}_{2}$ & 340.5 & - \\
\hline 49. & & 29.7 & $\begin{array}{l}\text { 4-[[4-[(4-hydroxy-2,6-dimethylphenyl)diazenyl]- } \\
\text { 2,3-dimethylphenyl]diazenyl]-3,5-dimethylphenol }\end{array}$ & - & $\mathrm{C}_{24} \mathrm{H}_{26} \mathrm{~N}_{4} \mathrm{O}_{2}$ & 402.5 & \\
\hline
\end{tabular}

in (Table 2). The concentration of tannins in the extracts is present in the order as Aqueous $>$ Methanol $>$ Hexane $>$ Ethyl acetate $>$ Chloroform $>$ Pet ether. The total phenolic content is high in aqueous fraction and decreases in subsequent order as Aqueous $>$ Methanol $>$ Ethyl acetate $>-$ Hexane $>$ Chloroform $>$ Pet ether. The total flavonoids in the extracts were determined in terms of $\mathrm{mg}$ of Quercetin equivalents per $g$ extract (mg QE/g), and the results were given in (Table 2). Highest flavonoid concentration was found to be present in aqueous extract followed by methanol $>$ ethyl acetate $>$ chloroform $>$ hexane $>$ pet ether.

\section{Radical scavenging activity}

In the present investigation, radical scavenging property of $E$. alsinoides extracts was assessed with three independent experiments, and the values were expressed as mean \pm SEM. The most potent activity $\left(\mathrm{IC}_{50}\right.$ of $52.43 \mu \mathrm{g} /$
$\mathrm{mL}$ ) was observed with aqueous extract, trailed by methanolic extracts $\left(\mathrm{IC}_{50}\right.$ of $\left.61.55 \mu \mathrm{g} / \mathrm{mL}\right)$.

\section{Metal reducing power}

E. alsinoides extracts showed a decreasing potency in FRAP assay as Water $>$ Methanol $>$ Ethyl acetate $>$ Hexane $>$ Chloroform $>$ Pet ether. Table 3 illustrates the results of antioxidant studies using the extracts of E. alsinoides.

\section{Acetylcholinesterase inhibitory activity}

In the present study, anti-Alzheimer's potential of $E$. alsinoides was determined. The inhibitory potential of aqueous and methanol fractions was more active in inhibiting AChE than the standard anti-Alzheimer's drug, galantamine. In contrast, the inhibiting property of other extracts was weak towards AChE (Table 4).

Table 2 Tannins, Total Phenolics and Total Flavanoides in the extracts of E. alsinoides (Linn.) Linn

\begin{tabular}{|c|c|c|c|c|}
\hline S.No. & Fraction & Tannins (mg GAE/g) & Total Phenolics (mg GAE/g) & Total flavanoides (mg QE/g) \\
\hline 1. & $P$ & $0.90 \pm 0.02$ & $2.04 \pm 0.02$ & $4.79 \pm 0.02$ \\
\hline 2. & $\mathrm{H}$ & $8.92 \pm 0.02$ & $9.69 \pm 0.02$ & $20.83 \pm 0.02$ \\
\hline 3. & C & $7.44 \pm 0.01$ & $6.38 \pm 0.03$ & $39.38 \pm 0.03$ \\
\hline 4. & EA & $8.57 \pm 0.01$ & $10.22 \pm 0.02$ & $55.03 \pm 0.01$ \\
\hline 5. & M & $23.28 \pm 0.01$ & $27.64 \pm 0.03$ & $62.26 \pm 0.01$ \\
\hline 6. & W & $45.08 \pm 0.02$ & $49.30 \pm 0.07$ & $211.21 \pm 0.02$ \\
\hline
\end{tabular}


Table 3 Antioxidant studies using the extracts of Evolvulus alsinoides (Linn.) Linn

\begin{tabular}{llll}
\hline S.No. & Fraction & DPPH assay $I C_{50} \mu \mathrm{g} / \mathrm{ml}$ & $\begin{array}{l}\text { FRAP assay } \\
\text { IC } 50 \mathrm{\mu g} / \mathrm{ml}\end{array}$ \\
\hline 1. & $\mathrm{P}$ & $117.45 \pm 0.06$ & $115.72 \pm 0.03$ \\
2. & $\mathrm{H}$ & $88.21 \pm 0.07$ & $88.63 \pm 0.02$ \\
3. & $\mathrm{C}$ & $95.85 \pm 0.95$ & $96.52 \pm 0.04$ \\
4. & EA & $78.33 \pm 2.2$ & $79.92 \pm 0.03$ \\
5. & $\mathrm{M}$ & $61.55 \pm 0.6$ & $64.16 \pm 0.02$ \\
6. & W & $52.43 \pm 0.2$ & $41.58 \pm 0.03$ \\
7. & Standard $^{\mathrm{a}}$ & $68.49 \pm 0.09$ & $71.05 \pm 0.02$ \\
\hline
\end{tabular}

a Butylated hydroxy toluene for DPPH assay and Ascorbic acid for FRAP assay

\section{a-Amylase and a-glucosidase inhibitory activity}

All the extracts except hexane fraction showed intense $\alpha$-glucosidase inhibitory activity. Methanol and water extractives showed healthy $\alpha$-amylase inhibitory activity, whereas chloroform, hexane and ethyl acetate fractions showed weak activity towards $\alpha$-amylase inhibition (Table 4 and Fig. 1). The antidiabetic drug, Acarbose, with $\mathrm{IC}_{50} 6.46 \mathrm{mg} / \mathrm{mL}$ in the $\alpha$-glucosidase assay and $1.32 \mathrm{mg} / \mathrm{mL}$ in the $\alpha$-amylase assay was used as a standard.

\section{Cytotoxicity studies using SH-SY5Y cell line by MTT assay} The cytotoxic study of E. alsinoides (Fig. 2) on SH-SY5Y neuroblastoma cell line using MTT assay showed an $\mathrm{IC}_{50}$ value of $103.0035 \mu \mathrm{g} / \mathrm{mL}$ at $70-80 \%$ confluency with the percentage viability as $24.7,45.03,59.53,74.36$ at $250,125,62.5,31.25 \mu \mathrm{g} / \mathrm{mL}$.

\section{Correlation between assays}

The statistical relationship between the assays was determined by correlation analysis using SPSS tool. The $p$ values resulted from correlation analysis are given in Table 5. The DPPH assay showed a high, positive and significant correlation with $\alpha$ - amylase, $\alpha$ - glucosidase and acetylcholinesterase inhibition $(r=0.980,0.909$ and 0.989, $p<0.05)$. Similarly, high, positive and significant

Table 4 Enzyme inhibitory activity of the extracts of Evolvulus alsionoides (Linn.) Linn

\begin{tabular}{lllll}
\hline S.No. & Extract & $\begin{array}{l}a-\text { Amylase } \\
\mid C_{50}, \mu \mathrm{g} / \mathrm{ml}\end{array}$ & $\begin{array}{l}a-\text { Glucosidase } \\
\mid C_{50}, \mu \mathrm{g} / \mathrm{ml}\end{array}$ & $\begin{array}{l}\text { Acetyl cholinesterase } \\
\mathrm{C}_{50}, \mu \mathrm{g} / \mathrm{ml}\end{array}$ \\
\hline 1. & $\mathrm{H}$ & $12.35 \pm 0.2$ & $8.10 \pm 0.1$ & $6.61 \pm 0.07$ \\
2. & $\mathrm{C}$ & $14.96 \pm 0.05$ & $11.19 \pm 0.13$ & $7.55 \pm 0.08$ \\
3. & $\mathrm{EA}$ & $7.65 \pm 0.1$ & $4.82 \pm 0.14$ & $6.03 \pm 0.03$ \\
4. & $\mathrm{M}$ & $1.33 \pm 0.05$ & $3.80 \pm 0.09$ & $4.77 \pm 0.04$ \\
5. & $\mathrm{W}$ & $1.34 \pm 0.08$ & $3.58 \pm 0.02$ & $4.46 \pm 0.03$ \\
6. & Standard $^{\mathrm{a}}$ & $1.32 \pm 0.15$ & $6.46 \pm 0.1$ & $2.59 \pm 0.09$ \\
\hline
\end{tabular}

${ }^{a}$ Acarbose was used as the standard drug in a-amylase and a-glucosidase assays, galantamine in acetylcholinesterase correlations were observed between FRAP assay and the enzyme inhibition studies with $r=0.920,0.841$ and 0.947 for $\alpha$ - amylase, $\alpha$ - glucosidase and acetylcholinesterase enzymes with $p<0.05$. A strong positive correlation with $r=0.988, p<0.01$ is found between alpha-amylase and Acetylcholinesterase inhibitions and a positive correlation with $r=0.944, p<0.05$ exists between alphaglucosidase and Acetylcholinesterase inhibitions.

\section{Discussion \\ GCMS analyses}

GCMS analysis was carried out to determine the possible chemical constituents from Evolvulus alsinoides (L.) L. Analysis of the chromatograms obtained with $E$. alsinoides solvent fractions (Fig. 3) validates the presence of various therapeutically significant phytocompounds. The extracts were found to be rich in aromatic amines, phenols and aromatic phenols that are potent antioxidants in nature.

\section{Estimation of plant Phenolics}

Phenolic acids, flavonoids, and tannins are grouped as plant phenolics. The plant phenolics are regarded to possess potent antioxidant properties that are significant in the prevention of various oxidative stress associated diseases [33]. The results show that the high polar solvents are more useful for extracting antioxidant compounds from plant sources [34]. The polar and aqueous solvents are efficient in the extraction of plant phenolics [35]. The polyphenols have a polarity range between polar and non-polar. Optimum extraction of these aromatic compounds with better efficiency is a result of solvation in the polar solvents due to the interactions between the polar sites of these antioxidant compounds and the solvent [36]. The plant phenolics in the plant sample had polar properties, thus making the polar solvents effective in the extraction. Regression analysis of the obtained results showed a polarity dependent increase with extraction yield, phytochemical content and radical scavenging potency of the extracts [37].

\section{Radical scavenging activity}

The radical scavengers and antioxidant compounds are valuable dietary supplements that protect the human body from various disorders. Radical scavenging assay using DPPH prevails to be a consistent method for determining the antioxidant capacity of natural and synthetic biomolecules. This method is empathetic even with weak antioxidants as DPPH reacts and adequate time specified in the protocol allows DPPH to respond with the free radicals gradually. The technique can be adopted with aqueous and nonpolar organic solvents to examine both hydrophilic and lipophilic antioxidants [38]. The lower value of $\mathrm{IC}_{50}$ indicates a higher 


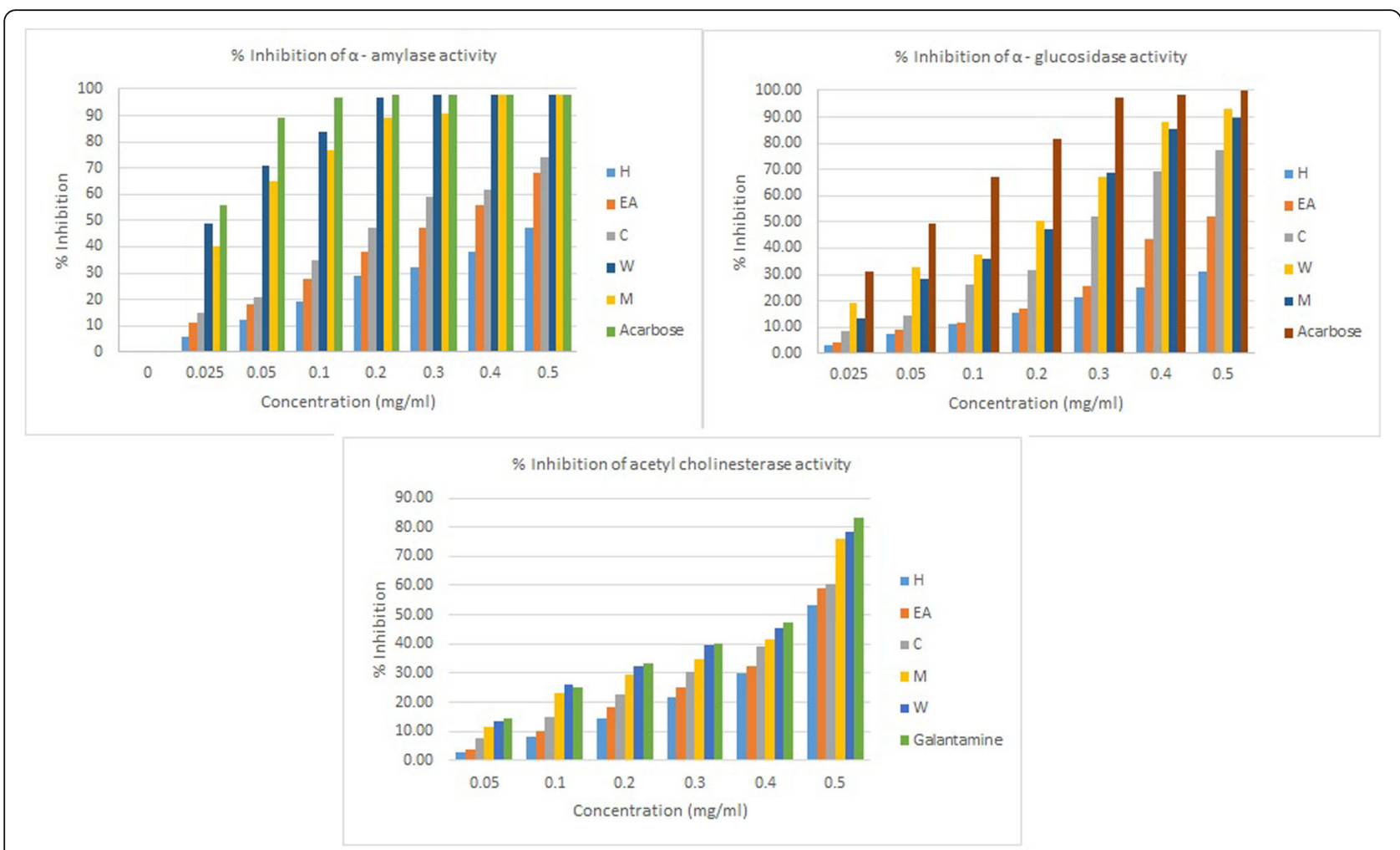

Fig. 1 Percentage inhibition of the enzymes by E.alsinoides (L.) L. leaf extracts

antioxidant activity [39]. The aqueous extract appears to be more effective than BHT in scavenging DPPH radicals. Shreds of evidence showing a positive correlation between DPPH assay and phenolics have been reported validating the significant contributions of plant phenolics in the DPPH radical scavenging activity [40].
A similar result was shown with Rhus coriaria L. fruit extracts, in which higher antioxidant activity was observed with the water extracts than ethanol solubles [41]. The significance of extracting solvent in altering the antioxidant property of wheat bran has been studied recommending high polar solvents for phenolic

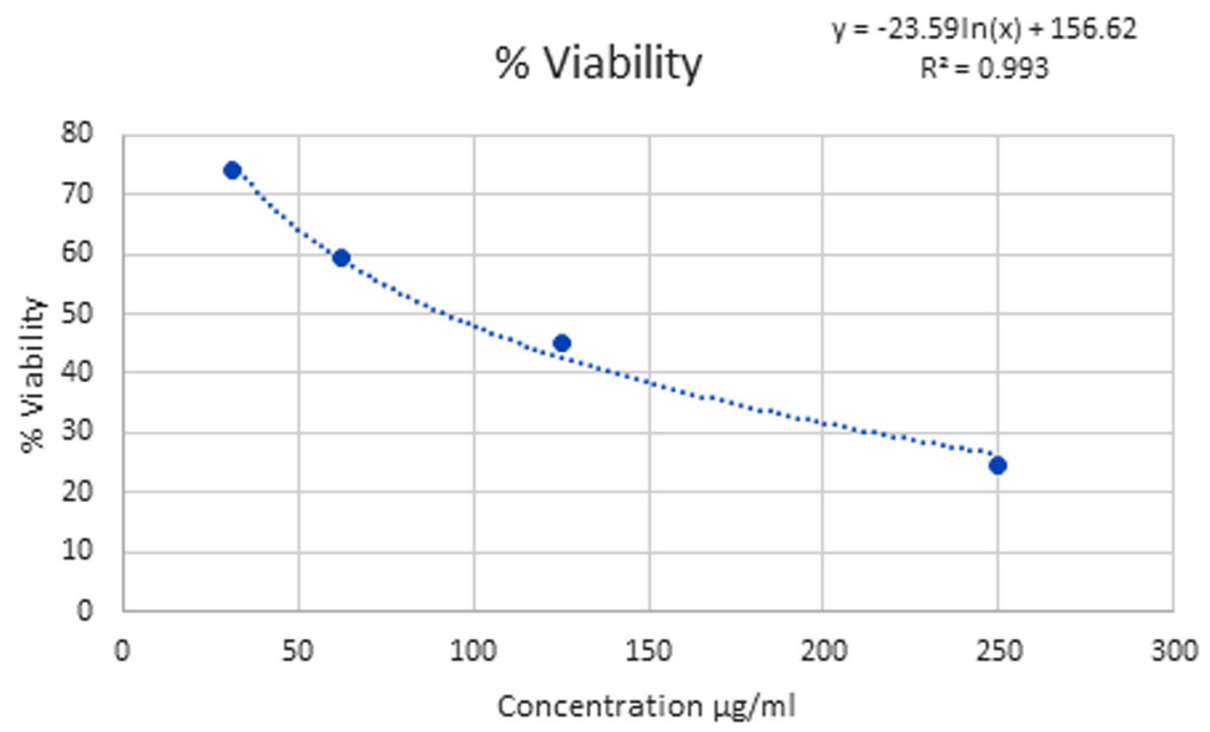

Fig. 2 Cytotoxic Study of E.alsinoides(L.) L. Leaf extract 
Table 5 Pearson's correlation coefficients of antioxidant activities, a-amylase inhibition, a - glucosidase and acetylcholinesterase inhibition of the extracts

\begin{tabular}{|c|c|c|c|c|c|}
\hline & DPPH assay & FRAP assay & $a-$ Amylase & $a-$ Glucosidase & Acetyl cholinesterase \\
\hline$\overline{D P P H}$ assay & 1 & $0.979^{\mathrm{a}}$ & $0.980^{\mathrm{a}}$ & $0.909^{b}$ & $0.989^{\mathrm{a}}$ \\
\hline FRAP assay & & 1 & $.920^{\mathrm{b}}$ & 0.841 & $0.947^{b}$ \\
\hline$a-$ Amylase & & & 1 & $0.945^{b}$ & $0.988^{\mathrm{a}}$ \\
\hline$a-$ Glucosidase & & & & 1 & $0.944^{b}$ \\
\hline Acetyl cholinesterase & & & & & 1 \\
\hline
\end{tabular}

a. Correlation is significant at the 0.01 level (2-tailed)

b. Correlation is significant at the 0.05 level (2-tailed)

antioxidants [42]. Studies with Limnophila aromatica reported that phenolic acids and flavonoids in the plant extracts were consistent with each other and also their antioxidant activity. Incidence of plant phenolics at prominent levels in the aqueous extract might be owing to the proton-donor and electron-transfer potentialities [43].

\section{Metal reducing power}

The metal-reducing capacity of biomolecules is estimated to be a vital indicator of its antioxidant property. The rate of $\mathrm{Fe}^{3+}$ cyanide complex reduction to its ferrous form was measured. The increased, reducing ability of the extracts was determined through the higher absorbance at $700 \mathrm{~nm}$. The results are in correlation with the values obtained through DPPH assay [44]. Due to deficient concentration of phenolics and flavonoids and weak antioxidant activity with DPPH and FRAP, pet ether extract was not used for enzyme inhibition studies. The impact of solvent polarity in influencing the dissolution of antioxidant compounds was ascertained [45].

\section{Acetylcholinesterase inhibitory activity}

The acetylcholinesterases inhibition masters to be a competent approach in Alzheimer's management [46]. The acetylcholinesterase inhibitors stop the metabolism of acetylcholine [47] increasing neurotransmission [48]. As per the Cholinergic hypothesis, the reduction in acetylcholine (ACh) synthesis leads to AD. Hence, potential therapeutic strategies increase cholinergic levels by inhibiting acetylcholinesterase (AChE) biological activity [49]. Flavonoids claim to be new multipotent leads for $\mathrm{AD}$ management owing to significant $\mathrm{AChE}$ inhibitory and antioxidant activities [50]. A bioassayguided fractionation aids in the extraction and isolation of anti-AChE components from the plant extracts [51]. The flavonoids and other phenolic molecules bind to peripheral anionic sites on the Acetylcholinesterase [47]. The polyphenolic compounds with potential AChE inhibitory property and antioxidant activity have been reported [48].

Shankhapushpi is recognized in the Indian system of medicine to improve cognitive function [52]. The results support the use of $E$. alsinoides as a brain tonic in

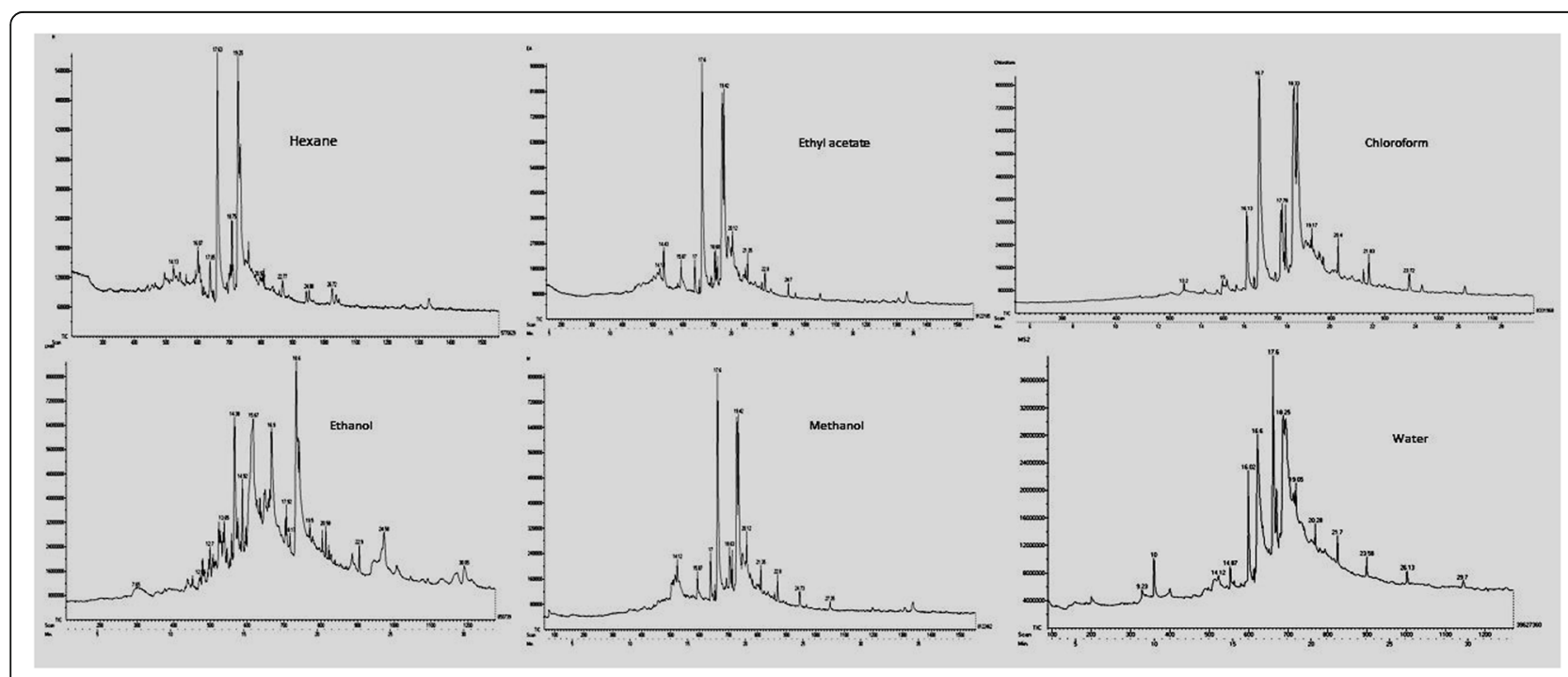

Fig. 3 GCMS Chromatogram of organic and alcoholic extracts of E. alsinoides (L.) L. leaf 
ayurvedic medicine [2]. The secondary metabolites from medicinal plants lessen neuronal dysfunctions by plummeting AChE activity in various regions of the brain [53]. The bioactive that acts on the cholinergic function of the central nervous system are significant in treating Alzheimer's' Disease [54].

\section{a-Amylase and a-glucosidase inhibitory activity}

The methanol and water extracts showed the strongest $\alpha$-amylase and $\alpha$-glucosidase inhibitory property. Chloroform fraction exhibited week $\alpha$-amylase and $\alpha$ glucosidase activities. A positive correlation between antioxidant and antidiabetic properties with the flavonoids content has been reported [55]. A dose-dependent percentage inhibitory activity of the plant extract against alpha-amylase and alpha-glucosidase enzymes was reported.

\section{Cytotoxicity studies using SH-SY5Y cell line by MTT assay} The results indicate significant dose-dependent inhibition on the growth of SHSY5Y cells with the water extract of E. alsinoides leaf. Hence, the water extract of the plant leaves should possess anti-cancerous components that inhibit the growth of SH-SY5Y cell lines. The protective effects of flavonoid-rich extracts support the use of these compounds in the management of oxidative stress-related neurodegenerative diseases such as Alzheimer's disease and Parkinson's disease in vitro [36]. The biological activity of these phenolics is consistent with a synergy between them.

\section{Correlation between assays}

The high correlations between the variables support the fact that some set of bioactive in the extracts could be ascribed for its enzyme inhibitory activities [56]. The antioxidant abilities of the plant extract obtained through FRAP assay and DPPH assay were highly correlated signifying that antioxidants in the extracts were capable of scavenging free radicals and reducing oxidants.

Correlation analysis exploring the relationships between the plant phenolics and different antioxidant variables measured in Halimium halimifolium reported a linear correlation between antioxidant activity and the plant phenolics [57]. A relatively positive relationship was reported between the phenolics, flavonoids, tannins and their radical scavenging potency in Rubus spp. [58]. The plant phenolics possess the ability to scavenge free radicals formed during glycation. Hence DPPH scavenging activity and enzyme inhibition showed a strong positive correlation with anti-oxidant rich extracts. Correlation analysis performed in the present work substantiates that $\alpha$ amylase, $\alpha$-glucosidase, and acetylcholinesterase inhibition potential of were attributed with radical scavenging property of the plant extracts.

\section{Conclusion}

Bioactivity-guided screening of biomolecules prevails to be a cost-effective strategy in developing lead molecules for various ailments. From the present research, the leaf extracts of E. alsinoides exhibit remarkable inhibitory activity with the methanolic and water extract against $\alpha-$ amylase and $\alpha-$ glucosidase. Also, the methanol and water extracts possess significant acetylcholinesterase activity. Hence leaves of $E$. alsinoides has the potential to be used in ayurvedic decoctions in controlling and treatment of Type II diabetes mellitus and neurodegenerative diseases. The effect of solvent fractions in inhibiting the enzymes and neuroblastoma cell line growth in a dosedependent fashion was also validated. Furthermore, the results obtained in the current research have opened opportunities for further study in searching novel effective drugs of pharmaceutical importance. Therefore, E. alsinoides (L.) L. can be recommended as a plant of significant potential. The current findings expounded that $E$. alsinoides (L.) L., due to its inherent plant phenolics and antioxidant activities, possess enzyme inhibitory properties supporting its traditional application in the management of $\mathrm{AD}$ and Diabetes Mellitus. Yet, additional studies with model animals Alzheimer's disease is required to elucidate the invivo efficacy of $E$. alsinoides (L.) L. methodical.

\section{Abbreviations}

DPPH: 2,2-diphenyl-1-picrylhydrazyl; FRAP: Ferric Reducing Ability of Plasma; AD: Alzheimer's Disease; AChE: Acetylcholine Esterase; AB: beta-amyloid peptide; TPC: Total Phenolic Compounds; TFC: Total Flavonoid Compounds; BHT: Butylated hydroxytoluene; TPTZ: 2,4,6-tripyridyl-S-triazine

\section{Acknowledgements}

We express our indebtedness and sense of gratitude to Chairman, Trustee, and Principal of Bannari Amman Institute of Technology, Sathyamangalam for providing the necessary facilities to perform the experiments in the Department of Biotechnology. We acknowledge the National Biodiversity Authority, Chennai. for permission to enter the Forest of Western Ghat, Sathyamangalm. The authors are grateful to Divisional Forest Officer and Field Director, Tamil Nadu Forest Department, Sathyamangalam and Haasanur Division for their kind help during plant sample collection (Ref.No.WL5(A)/25814/2015). The authors are thankful to Dr.G.V.S.Murthy, Scientist ' $G$ ' and Head of Office, Botanical Survey of India, Tamil Nadu, India for plant authentication. The authors are also thankful to Dr. Ashish Devidas Wadhwani, JSS College of Pharmacy, Ooty, India, for helping us to perform cytotoxicity studies.

\section{Authors' contributions}

Both the authors are involved in laboratory determinations, interpretation of data, and drafting the manuscript. The author(s) read and approved the final manuscript.

\section{Funding}

The research was self - supported

\section{Availability of data and materials}

The datasets analyzed in the study can be made available by the corresponding author upon reasonable request.

Ethics approval and consent to participate Not applicable. 


\section{Consent for publication}

Not applicable.

\section{Competing interests}

The authors declare that they have no competing interests.

\section{Received: 8 February 2020 Accepted: 7 April 2020}

\section{Published online: 28 April 2020}

\section{References}

1. Gupta P, Akanksha, Siripurapu KB, Ahmad A, Palit G, Arora A, et al. Antistress constituents of Evolvulus alsinoides: an Ayurvedic crude drug. Chem Pharm Bull. 2007:55:771-5.

2. Sethiya N, Nahata A, Mishras H, Dixit V. An pdate on Shankhpushpi, a cognition boosting Ayurvedic medicine. Zhong Xi Yi Jie He Xue Bao. 2009;7: 1001-22.

3. Massoulié J, Pezzementi L, Bon S, Krejci E, Vallette F-M. Molecular and cellular biology of cholinesterases. Prog Neurobiol. 1993;41:31-91. https:// doi.org/10.1016/0301-0082(93)90040-Y.

4. Howes M-JR, Houghton PJ. Plants used in Chinese and Indian traditional medicine for improvement of memory and cognitive function. Pharmacol Biochem Behav. 2003;75:513-27. https://doi.org/10.1016/S00913057(03)00128-X

5. Tamil IG, Dineshkumar B, Nandhakumar M, Senthilkumar M, Mitra A. In vitro study on a-amylase inhibitory activity of an Indian medicinal plant, Phyllanthus amarus. Indian J Pharmacol. 2010;42:280-2. https://doi.org/10. 4103/0253-7613.70107.

6. Haq I, Mirza B, Kondratyuk TP, Park E-J, Burns BE, Marler LE, et al. Preliminary evaluation for cancer chemopreventive and cytotoxic potential of naturally growing ethnobotanically selected plants of Pakistan. Pharm Biol. 2013;51: 316-28. https://doi.org/10.3109/13880209.2012.728612.

7. Uddin MN, Afrin R, Uddin MJ, Uddin MJ, Alam AHMK, Rahman AA, et al. Vanda roxburghii chloroform extract as a potential source of polyphenols with antioxidant and cholinesterase inhibitory activities: identification of a strong phenolic antioxidant. BMC Complement Altern Med. 2015;15:195. https://doi.org/10.1186/s12906-015-0728-y.

8. Citron M. Alzheimer's disease: strategies for disease modification. Nat Rev Drug Discov. 2010;9:387-98. https://doi.org/10.1038/nrd2896.

9. Inestrosa NC, Dinamarca MC, Alvarez A. Amyloid-cholinesterase interactions. FEBS J. 2008;275:625-32. https://doi.org/10.1111/j.1742-4658.2007.06238.x.

10. Taylor P, Radic Z. The Cholinesterases: from genes to proteins. Annu Rev Pharmacol Toxicol. 1994;34:281-320. https://doi.org/10.1146/annurev.pa.34 040194.001433.

11. Härtig W, Goldhammer S, Bauer U, Wegner F, Wirths O, Bayer TA, et al. Concomitant detection of $\beta$-amyloid peptides with $\mathrm{N}$-terminal truncation and different $\mathrm{C}$-terminal endings in cortical plaques from cases with Alzheimer's disease, senile monkeys and triple transgenic mice. J Chem Neuroanat. 2010:40:82-92. https://doi.org/10.1016/j.jchemneu.2010.03.006.

12. Talesa VN. Acetylcholinesterase in Alzheimer's disease. Mech Ageing Dev. 2001;122:1961-9. https://doi.org/10.1016/S0047-6374(01)00309-8.

13. Li X, Song D, Leng SX. Link between type 2 diabetes and Alzheimer's disease: from epidemiology to mechanism and treatment. Clin Interv Aging. 2015;10:549-60. https://doi.org/10.2147/CIA.S74042.

14. de Matos AM, de Macedo MP, Rauter AP. Bridging type 2 diabetes and Alzheimer's disease: assembling the puzzle pieces in the quest for the molecules with therapeutic and preventive potential. Med Res Rev. 2018;38: 261-324. https://doi.org/10.1002/med.21440

15. Thrasher J, Surks H, Nowotny I, Pierre S, Rotthaeuser B, Wernicke-Panten K, et al. Safety of insulin Lispro and a biosimilar insulin Lispro when administered through an insulin pump. J Diabetes Sci Technol. 2018;12:6806. https://doi.org/10.1177/1932296817753644.

16. Gerich J. Pathogenesis and management of postprandial hyperglycemia: role of incretin-based therapies. Int J Gen Med. 2013:6:877-95. https://doi. org/10.2147/IJGM.S51665.

17. Etxeberria U, de la Garza AL, Campión J, Martínez JA, Milagro Fl. Antidiabetic effects of natural plant extracts via inhibition of carbohydrate hydrolysis enzymes with emphasis on pancreatic alpha amylase. Expert Opin Ther Targets. 2012;16:269-97. https://doi.org/10.1517/14728222.2012.664134.

18. Rahimi R, Nikfar S, Larijani B, Abdollahi M. A review on the role of antioxidants in the management of diabetes and its complications. Biomed Pharmacother. 2005;59:365-73. https://doi.org/10.1016/j.biopha.2005.07.002.
19. Gonzàlez JA, Reimann F, Burdakov D. Dissociation between sensing and metabolism of glucose in sugar sensing neurones. J Physiol. 2009;587:41-8. https://doi.org/10.1113/jphysiol.2008.163410.

20. Das L, Bhaumik E, Raychaudhuri U, Chakraborty R. Role of nutraceuticals in human health. J Food Sci Technol. 2012;49:173-83. https://doi.org/10.1007/ s13197-011-0269-4.

21. Dash GK, Suresh P, Sahu SK, Kar DM, Ganapaty S, Panda SB. Evaluation of Evolvulus alsinoides Linn. For anthelmintic and antimicrobial activities. J Nat Remedies. 2002;2:182-5.

22. Handa. In Reply: Behaviour therapy. Extr Technol Med Aromat Plants. 2008.

23. Khan M, Ganie SA, Wani IH, Ganai BA, Masood A, Zargar MA, et al. Free radical scavenging activity of Elsholtzia densa. JAMS J Acupunct Meridian Stud. 2012:5:104-11.

24. Barreira JCM, Ferreira ICFR, Oliveira MBPP, Pereira JA. Antioxidant activities of the extracts from chestnut flower, leaf, skins and fruit. Food Chem. 2008;107: 1106-13.

25. Hsu F-L, Huang W-J, Wu T-H, Lee M-H, Chen L-C, Lu H-J, et al. Evaluation of antioxidant and free radical scavenging capacities of polyphenolics from pods of Caesalpinia pulcherrima. Int J Mol Sci. 2012;13:6073-88. https://doi. org/10.3390/ijms13056073.

26. Benzie IFF, Strain JJ. [2] Ferric reducing/antioxidant power assay: Direct measure of total antioxidant activity of biological fluids and modified version for simultaneous measurement of total antioxidant power and ascorbic acid concentration. Methods Enzymol. 1999;299:15-27. https://doi. org/10.1016/S0076-6879(99)99005-5.

27. Bahadori MB, Dinparast L, Zengin G, Sarikurkcu C, Bahadori S, Asghari B, et al. Functional components, antidiabetic, anti-Alzheimer's disease, and antioxidant activities of Salvia syriaca L. Int J Food Prop. 2017;20:1761-72. https://doi.org/10.1080/10942912.2016.1218893.

28. Zengin G, Sarikurkcu C, Aktumsek A, Ceylan R. Antioxidant potential and inhibition of key enzymes linked to Alzheimer's diseases and diabetes mellitus by Monoterpene-rich essential oil from Sideritis galatica Bornm. Endemic to Turkey Rec Nat Prod. 2016;75:42-50

29. Yang D, Zhao J, Liu S, Song F, Liu Z. The screening of potential aglucosidase inhibitors from the Polygonum multiflorum extract using ultrafiltration combined with liquid chromatography-tandem mass spectrometry. Anal Methods. 2014;6:3353-9. https://doi.org/10.1039/ C4AY00064A.

30. Patte-Mensah C, Meyer L, Schaeffer V, Eckert A, Mensah-Nyagan AG. Transfection of human neuroblastoma cells with Alzheimer's disease brain hallmarks as a promising strategy to investigate the role of Neurosteroidogenesis in Neuroprotection. In: Biovalley Monographs; 2013. p 50-9. https://doi.org/10.1159/000339189.

31. Kurokawa M, Wadhwani A, Kai H, Hidaka M, Yoshida H, Sugita C, et al. Activation of cellular immunity in herpes simplex virus type 1-infected mice by the Oral Administration of Aqueous Extract of Moringa oleifera lam. Leaves Phyther Res. 2016:30:797-804.

32. Atolani O, Oguntoye $H$, Areh ET, Adeyemi OS, Kambizi L. Chemical composition, anti-toxoplasma, cytotoxicity, antioxidant, and antiinflammatory potentials of Cola gigantea seed oil. Pharm Biol. 2019;57:15460. https://doi.org/10.1080/13880209.2019.1577468.

33. Dai J, Mumper RJ. Plant Phenolics: extraction, analysis and their antioxidant and anticancer properties. Molecules. 2010;15:7313-52. https://doi.org/10. 3390/molecules15107313.

34. Boscariol Rasera G, Hilkner MH, de Alencar SM, de Castro RJS. Biologically active compounds from white and black mustard grains: an optimization study for recovery and identification of phenolic antioxidants. Ind Crop Prod. 2019:135:294-300. https://doi.org/10.1016/j.indcrop.2019.04.059.

35. Shi J, Nawaz H, Pohorly J, Mittal G, Kakuda Y, Jiang Y. Extraction of Polyphenolics from plant material for functional foods-engineering and technology. Food Rev Int. 2005;21:139-66. https://doi.org/10.1081/FRI200040606

36. Liu X, Dong M, Chen X, Jiang M, Lv X, Yan G. Antioxidant activity and phenolics of an endophytic Xylaria sp. from Ginkgo biloba. Food Chem. 2007;105:548-54. https://doi.org/10.1016/j.foodchem.2007.04.008.

37. Nawaz H, Aslam M, Muntaha ST. Effect of solvent polarity and extraction method on phytochemical composition and antioxidant potential of corn silk. Free Radicals Antioxidants. 2019:9:05-11.

38. Kasote DM, Katyare SS, Hegde MV, Bae H. Significance of antioxidant potential of plants and its relevance to therapeutic applications. Int J Biol Sci. 2015;11:982-91. https://doi.org/10.7150/ijbs.12096. 
39. Murugan R, Arunachalam K, Parimelazhagan T. Antioxidant, antiinflammatory activity, and phytochemical constituents of ficus (Ficus amplissima smith) bark. Food Sci Biotechnol. 2012;21:59-67.

40. Anggraini T, Wilma S, Syukri D, Azima F. Total phenolic, anthocyanin, Catechins, DPPH radical scavenging activity, and toxicity of Lepisanthes alata (Blume) Leenh. Int J Food Sci. 2019;2019:9703176. https://doi.org/10. 1155/2019/9703176

41. Bursal E, Köksal E. Evaluation of reducing power and radical scavenging activities of water and ethanol extracts from sumac (Rhus coriaria L.). Food Res Int. 2011;44:2217-21. https://doi.org/10.1016/j.foodres.2010.11.001.

42. Zhou K, Yu L. Effects of extraction solvent on wheat bran antioxidant activity estimation. Lwt - Food Sci Technol. 2004;37:717-21.

43. Do QD, Angkawijaya AE, Tran-Nguyen PL, Huynh LH, Soetaredjo FE, Ismadji $S$, et al. Effect of extraction solvent on total phenol content, total flavonoid content, and antioxidant activity of Limnophila aromatica. J Food Drug Anal. 2014;22:296-302. https://doi.org/10.1016/j.jfda.2013.11.001.

44. Zhao H, Fan W, Dong J, Lu J, Chen J, Shan L, et al. Evaluation of antioxidant activities and total phenolic contents of typical malting barley varieties. Food Chem. 2008;107:296-304. https://doi.org/10.1016/j.foodchem.2007.08. 018.

45. Thouri A, Chahdoura H, El Arem A, Omri Hichri A, Ben Hassin R, Achour L. Effect of solvents extraction on phytochemical components and biological activities of Tunisian date seeds (var. Korkobbi and Arechti). BMC Complement Altern Med. 2017;17:248. https://doi.org/10.1186/s12906-017-1751-y.

46. Colović MB, Krstić DZ, Lazarević-Pašti TD, Bondžić AM, Vasić VM. Acetylcholinesterase inhibitors: pharmacology and toxicology. Curr Neuropharmacol. 2013;11:315-35. https://doi.org/10.2174/ $1570159 \times 11311030006$

47. Moore GJ, Moore SW. The Peripheral Anionic Site of Acetylcholinesterase: Structure, Functions and Potential Role in Rational Drug Design. Curr Pharm Design. 2006;12:217-25. https://doi.org/10.2174/138161206775193127.

48. Asaduzzaman M, Uddin MJ, Kader MA, Alam AHMK, Rahman AA, Rashid M, et al. In vitro acetylcholinesterase inhibitory activity and the antioxidant properties of Aegle marmelos leaf extract: implications for the treatment of Alzheimer's disease. Psychogeriatrics. 2014;14:1-10. https://doi.org/10.1111/ psyg.12031.

49. Ali Reza ASM, Hossain MS, Akhter S, Rahman MR, Nasrin MS, Uddin MJ, et al. In vitro antioxidant and cholinesterase inhibitory activities of Elatostema papillosum leaves and correlation with their phytochemical profiles: a study relevant to the treatment of Alzheimer's disease. BMC Complement Altern Med. 2018;18:123. https://doi.org/10.1186/s12906-018-2182-0.

50. Calvo IU-P, Calvo IM. Flavonoids as Acetylcholinesterase Inhibitors. Curr Med Chem. 2011;18:5289-302. https://doi.org/10.2174/092986711798184325.

51. Murray AP, Faraoni MB, Castro MJ, Alza NP, Cavallaro V. Natural AChE inhibitors from plants and their contribution to Alzheimer's disease therapy. Curr Neuropharmacol. 2013;11:388-413. https://doi.org/10.2174/ 1570159X11311040004.

52. Nag G \& De B. (2008). Antioxidant and acetylcholinesterase inhibitory properties of the Indian medicinal plant "Shankhapushpi" used for enhancing memory function. Journal of Complementary and Integrative Medicine, 5(1). https://doi.org/10.2202/1553-3840.1158.

53. Sharan PS, Ramsaneh R, Misha M, Ashish A, Kumar JS. Medicinal plants with acetylcholinesterase inhibitory activity. Rev Neurosci. 2018;29:491. https://doi.org/10.1515/revneuro-2017-0054.

54. Feitosa CM, Freitas RM, Luz NNN, Bezerra MZB, Trevisan MTS. Acetylcholinesterase inhibition by somes promising Brazilian medicinal plants. Brazilian J Biol. 2011;71:783-9 http://www.scielo.br/scielo.php?script= sci_arttext\&pid=S1519-69842011000400025\&nrm=iso.

55. Sarian MN, Ahmed QU, Mat So'Ad SZ, Alhassan AM, Murugesu S, Perumal V, et al. Antioxidant and antidiabetic effects of flavonoids: a structure-activity relationship based study. Biomed Res Int. 2017;2017:8386065.

56. Barchan A, Bakkali M, Arakrak A, Pagán R, Laglaoui A. The effects of solvents polarity on the phenolic contents and antioxidant activity of three Mentha species extracts. Int J Curr Microbiol Appl Sci. 2014;3:399-412.

57. Rebaya A, Belghith SI, Baghdikian B, Leddet VM, Mabrouki F, Olivier E, et al. Total phenolic, Total flavonoid, tannin content, and antioxidant capacity of Halimium halimifolium (Cistaceae). J Appl Pharm Sci. 2015;5:052-7.

58. Khalfallah A, Berrehal D, Bensouici C, Kabouche A, Semra Z, VoutquenneNazabadioko L, et al. Flavonoids, cytotoxic, antioxidant and antibacterial activities of Evax pygmaea. Pharm Biol. 2017;55:2292-6. https://doi.org/10. 1080/13880209.2017.1405997.

\section{Publisher's Note}

Springer Nature remains neutral with regard to jurisdictional claims in published maps and institutional affiliations.

\section{Ready to submit your research? Choose BMC and benefit from:}

- fast, convenient online submission

- thorough peer review by experienced researchers in your field

- rapid publication on acceptance

- support for research data, including large and complex data types

- gold Open Access which fosters wider collaboration and increased citations

- maximum visibility for your research: over $100 \mathrm{M}$ website views per year

At BMC, research is always in progress.

Learn more biomedcentral.com/submissions 